\title{
Phasic signaling in the bed nucleus of the stria terminalis during fear learning predicts within- and across-session cued fear expression
}

\author{
Max Bjorni, ${ }^{1}$ Natalie G. Rovero, ${ }^{1}$ Elissa R. Yang, ${ }^{1}$ Andrew Holmes, ${ }^{2}$ \\ and Lindsay R. Halladay ${ }^{1,2}$ \\ ${ }^{1}$ Department of Psychology, Santa Clara University, Santa Clara, California 95053, USA; ${ }^{2}$ Laboratory of Behavioral and Genomic \\ Neuroscience, National Institute on Alcohol Abuse and Alcoholism, National Institutes of Health, Rockville, Maryland 20852, USA
}

\begin{abstract}
While results from many past studies have implicated the bed nucleus of the stria terminalis (BNST) in mediating the expression of sustained negative affect, recent studies have highlighted a more complex role for BNST that includes aspects of fear learning in addition to defensive responding. As BNST is thought to encode ambiguous or unpredictable threat, it seems plausible that it may be involved in encoding early cued fear learning, especially immediately following a first tone-shock pairing when the conditioned stimulus-unconditioned stimulus (CS-US) contingency is not fully apparent. To investigate this, we conducted in vivo electrophysiological recording studies to examine neural dynamics of BNST units during cued fear acquisition and recall. We identified two functionally distinct subpopulations of BNST neurons that encode the intertrial interval (ITI) and may contribute to within- and across-session fear learning. "Ramping" cell activity during cued fear acquisition parallels the increase in freezing expression as mice learn the CS-US contingency, while

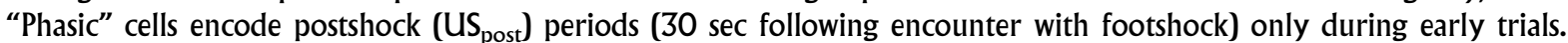
Importantly, the magnitude of Phasic unit responsivity to the first $\mathrm{US}_{\text {post }}$ period predicted not only freezing expression in response to the subsequent CS during acquisition, but also CS freezing evoked $24 \mathrm{~h}$ later during CS retrieval. These findings suggest for the first time that BNST activity may serve as an instructive signal during cued fear learning.
\end{abstract}

The ability to recognize threats and execute appropriate defensive responses is crucial for survival. Many decades of research have identified key players in the acquisition, expression, and extinction of fear, including the amygdala, hippocampus, and prefrontal cortex (Fendt and Fanselow 1999; LeDoux 2000; Maren 2001; Orsini and Maren 2012). Recent work has also focused on the bed nucleus of the stria terminalis (BNST) and its involvement in sustained negative affect. Currently, the role of the BNST in aversive learning has not been fully defined, but recent studies (for review, see Goode and Maren 2017) have highlighted a complex role for BNST in fear learning and defensive responding. Uncovering intricacies of its role in aversive learning will be crucial for the development of improved treatments for neuropsychological disorders related to negative affect.

Early work laid out a selective role for BNST in processing anxiety rather than fear; whereas explicit fear cues activate the amygdala, evidence suggested the BNST was important for processing information of longer duration and less specificity (LeDoux et al. 1988; Davis 1998). Two subsequent decades of work have improved this perhaps oversimplified distinction between amygdala versus BNST mediating fear versus anxiety. The BNST has since been identified as an important mediator of the limbic forebrain processes that encode aversive motivational states, specifically ambiguous or temporally unpredictable aversive cues (Davis et al. 2010; Daldrup et al. 2016; Goode and Maren 2017; Goode et al. 2019; Naaz et al. 2019).

Past studies have reported that BNST is necessary for fear learning involving long-duration, unpredictable, or contextual stimuli, but not for shorter-duration or explicit fear learning

\section{Corresponding author: LHalladay@scu.edu}

Article is online at http://www.learnmem.org/cgi/doi/10.1101//m.050807.119.
(LeDoux et al. 1988; Sullivan et al. 2004; Waddell et al. 2006). Notwithstanding this, more recent in vivo electrophysiological recording studies have revealed that some BNST neurons encode conditioned stimulus (CS) onset (Haufler et al. 2013), as well as fear expression during both contextual and cued fear recall (Marcinkiewcz et al. 2016). Importantly, our recent electrophysiological evidence showed that in the same animals, BNST neurons encoded fear expression as well as encounter with footshock (Marcinkiewcz et al. 2016), suggesting a dual role for BNST-not only predicting potential aversive encounters, but potentially also encoding sensory feedback following such an encounter. This raises the question of whether dynamic neural changes in BNST contribute to the fear learning process despite BNST not being necessary for cued fear learning.

Present understanding of the seeming unimportance for BNST in some types of aversive learning is in large part due to previous tests of necessity that used lesions or reversible inactivation (e.g., Gewirtz et al. 1998; Hammack et al. 2004; Sullivan et al. 2004; Waddell et al. 2006; Duvarci et al. 2009; Goode et al. 2015). With regard to fear learning, the brain is equipped with compensatory circuits that serve as secondary mechanisms for fear acquisition after damage to the "primary" fear circuit (Poulos et al. 2010; Zelikowsky et al. 2013). For example, BNST mediates fear learning following amygdala lesions (Poulos et al. 2010; but see Zimmerman and Maren 2011). As such, it seems plausible that the BNST encodes aspects of aversive learning in parallel

(C) 2020 Bjorni et al. This article is distributed exclusively by Cold Spring Harbor Laboratory Press for the first 12 months after the full-issue publication date (see http://learnmem.cshlp.org/site/misc/terms.xhtml). After 12 months, it is available under a Creative Commons License (Attribution-NonCommercial 4.0 International), as described at http://creativecommons.org/licenses/by-nc/4.0/. 
with the amygdala. That BNST neurons encode both behavioral expression and sensory input during fear acquisition (Marcinkiewcz et al. 2016) seems to support this hypothesis. But uncovering the extent to which BNST contributes to aversive learning alongside parallel circuits is not fully possible using lesions or inactivations which lack temporal precision and cannot easily parse primary versus compensatory circuitry. To this end, we used in vivo electrophysiology to observe the neural dynamics of the nonmanipulated BNST during cued fear acquisition, as well as both cued and contextual fear retrieval. Recordings revealed dynamic changes in the activity of two functional populations of BNST neurons that coincided with (and in some cases, predicted) both within- and across-session fear learning. These findings suggest for the first time that BNST activity may serve as an instructive signal during early fear learning.

\section{Results}

\section{Behavior during fear acquisition and retrieval}

On day 1 , mice $(n=10)$ acquired a fear response to the tone following five trials of CS + US pairings in Context A. Fear learning resulted in significantly different levels of CS-evoked freezing expression across trials (one-way repeated measures ANOVA; $F_{(5,45)}=23.7, P<0.0001 ;$ Fig. $1 \mathrm{~A}$, B). Planned post hoc comparisons revealed that relative to baseline, freezing during the CS was significantly elevated during trial $4\left(t_{(9)}=8.15, P<0.0001\right)$ and trial $5\left(t_{(9)}=7.20, P<0.0001\right)$. To assess whether freezing expression was specific to the tone cue (versus generalized fear during ITI or US ${ }_{\text {post }}$ periods), we ran a twoway repeated measures ANOVA (trial $\times$ period). Freezing levels differed significantly during CS-on and CS-off periods $\left(F_{(1,9)}=\right.$ $40.57, P<0.0001)$, and there was a significant interaction between trial and period $\left(F_{(1,9)}=58.20, P<0.001\right)$ because unlike during CS presentations, freezing during the ITI and US post $_{\text {periods did not increase }}$ across trials. CS-evoked freezing was significantly greater than ITI and US freezing during trial 4 (ITI: $t_{(9)}=6.33, P<$ 0.0001 ; $\left.\mathrm{US}_{\text {post }}: t_{(9)}=8.38, P<0.0001\right)$ and trial 5 (ITI: $t_{(9)}=5.13, P=0.001 ; \mathrm{US}_{\text {post }}: t_{(9)}=7.25, P<0.0001$ ). While there was a trend for an increase in both ITI and US post $_{\text {freez- }}$ ing versus baseline on trial 4 (ITI: $t_{(9)}=2.13, P=0.062$; US $_{\text {post }}: t_{(9)}=$ $1.54, P=0.15)$, none of the freezing levels during ITI or US post $_{\text {peri- }}$ ods differed significantly from baseline, indicating that across the acquisition session mice learned to discriminate the tone cue from the context.

Auditory fear memory was retrieved on day 2, when mice received 10 CS-only presentations in Context B. A one-way repeated
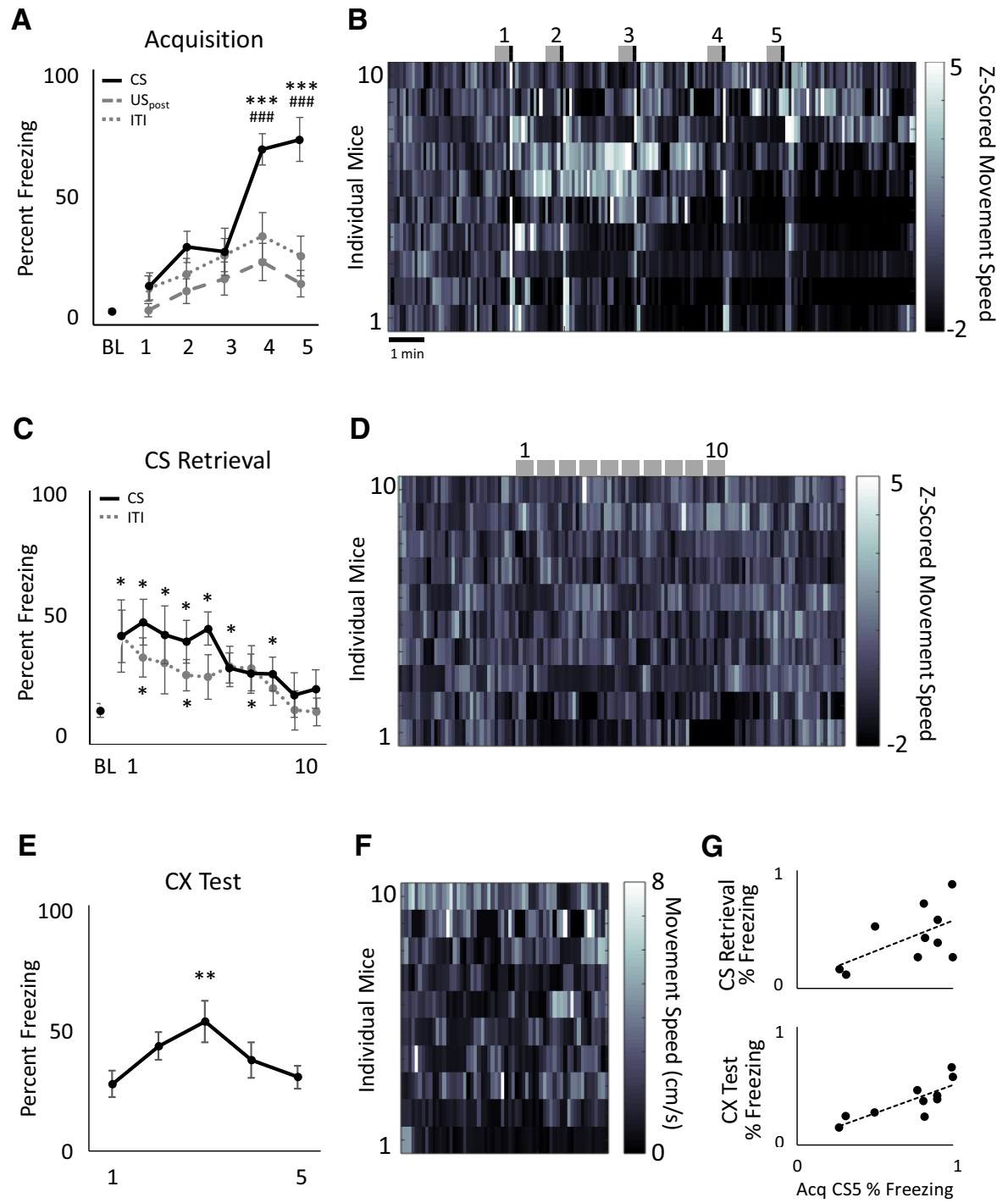

Figure 1. Freezing expression during cued fear acquisition, CS retrieval, and CX test. (A) Mice $(n=10)$ were trained to fear an auditory stimulus by pairing it with footshock in Context A. Freezing expression increased over the five acquisition trials, and was significantly different from baseline (noted by "**) as well as CS-off periods (noted by "\#") during trials 4 and 5. (B) Individual animals' movement speeds (normalized to baseline speeds) reflected US-induced movement and a reduction in movement during the CS and ITI over the course of the session. Gray boxes represent CS-on times, and black vertical bars indicate time of US delivery. (C) On day 2, mice received 10 CS presentations in Context B. Relative to baseline, the CS evoked freezing on trials 1-6, and 8. Significant freezing levels were observed during the ITI (relative to baseline) on trials 2, 4, and 7. (D) Individual animals' movement speed during the CS retrieval session, each normalized to its baseline movement speed. Gray boxes indicate CS-on times. $(E)$ On day 3 , mice returned to Context A for $5 \mathrm{~min}$ to assess contextual fear expression. Freezing was sig-

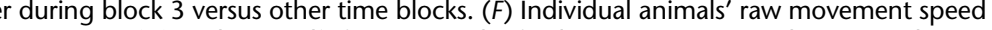
related with freezing expression during $C S$ retrieval (top) and $C X$ test (bottom). Data in $A, C$, and $E$ represent the mean \pm S.E.M. $\left({ }^{*}\right) P<0.05,\left({ }^{* *}\right) P<0.01,\left({ }^{* *}\right) P<0.001$, (\#\#\#)P<0.001.

measures ANOVA revealed significant differences in CS-evoked freezing across trials compared to baseline $\left(F_{(10,90)}=3.63, P<\right.$ 0.0001; Fig. 1C,D). CS-evoked freezing was elevated during trials $1-6\left(t_{(9)}=3.25,3.43,2.66,2.72,4.49,2.66, P<0.05\right)$ and $8\left(t_{(9)}=\right.$ $2.34, P=0.04)$. CS-evoked freezing significantly decreased across the session $\left(F_{(10,90)}=2.717, P=0.006\right)$, where average freezing during late trials (i.e., CS 6-10) was significantly attenuated compared to freezing during early trials (i.e., CS $1-5)\left(t_{(9)}=2.88, P=0.018\right)$. Freezing on retrieval day was not exclusive to CS-on periods; 
freezing during the ITI was also elevated relative to baseline and differed across trials $\left(F_{(10,90)}=3.73, P=0.047\right)$. ITI freezing was less prominent than CS-evoked freezing, however; relative to baseline, ITI freezing was only significantly elevated on trials $2\left(t_{(9)}=2.83\right.$, $P=0.03), 4\left(t_{(9)}=2.81, P=0.03\right)$, and $7\left(t_{(9)}=2.40, P=0.047\right)$, suggesting that mice exhibited both cue-evoked fear, and to a lesser extent, generalized fear during retrieval sessions.

To assess contextual fear memory, on day 3 mice were returned to Context A for 5 min in the absence of any CS or US presentations. Freezing was slightly elevated during minute 3 relative to the other time blocks $\left(F_{(4,36)}=5.174, P=0.002\right.$, Tukey's HSD $P<$ 0.01 ; Fig. 1D,E). Average time spent freezing during the CX test was similar to the levels seen on day 2 during CS retrieval, indicating that mice had acquired a fear response to both the discrete and contextual cues associated with fear learning.

Freezing expression during the final CS on acquisition day served as a reliable measure of fear learning for individual mice because it predicted freezing expression on subsequent test days (Fig. 1G). There was a strong trend for a positive correlation between acquisition-day CS 5 freezing and freezing during the CS on CS retrieval $(r=0.593, P=0.071)$. There was a significant positive correlation between acquisition-day CS5 freezing and freezing to the CX on day $3(r=0.81, P=0.005)$. As such, the degree to which each animal froze to the final CS during acquisition was predictive of fear expression in subsequent tests of both the discrete and contextual fear memories.

\section{Classification of BNST cell types}

Single units were classified based on their mean firing rate change across the acquisition session. For acquisition and CS retrieval sessions, the firing rate of each unit recorded was $Z$ score normalized against its average firing rate during the $3 \mathrm{~min}$ baseline period of the session. For CX test, unit firing rates were normalized to a 3 min homecage period immediately prior to the start of the session. Spike data for each recording session were used to generate a perievent time histogram $(\mathrm{PETH}$; bin size $=10 \mathrm{sec}$ ) aligned to session start for each unit. Bins with a Z score of $>2.58$ or $<-2.58$ were considered to significantly different than baseline. The inclusion of bins for each analysis are noted below.

Initial visual inspection of individual PETHs for acquisition (e.g., Fig. 2A) indicated consistent firing rate changes during the ITI (i.e., the time bins between US offset and subsequent CS onset) for many units, as opposed to bins occurring during CS-on periods. In fact, only three units out of the 79 recorded (3.8\%) significantly changed their firing rate during the CS and not the ITI (Fig. 2D), indicating that very few BNST neurons seem to solely encode the presence of a discrete fear stimulus. As such, $\mathrm{Z}$ scores from the six time bins immediately following offset of the US (i.e., first min of each ITI) were used to classify cells into subtypes. Units exhibiting significant firing rate changes during the 60 -sec initial ITI period were considered to be cells that "encode" stimuli and/or behavior taking place during that time, but were not assumed to necessarily drive behavior.

Units were classified into three groups-Phasic, Ramping, and no response (Fig. 2B-F). A large proportion of units recorded (43\%, 34 of 79) exhibited phasic significant firing rate changes during at least one of the first 3 ITIs, but specifically returned to baseline firing rate by ITI 4 , and thus were classified as Phasic units (e.g., Fig. 2 A top, middle). About one fourth of recorded units ( $24 \%, 19$ of 79 ) exhibited significant firing rate changes during or after the first ITI that persisted, and in many cases increased in magnitude or duration, throughout the rest of the session (e.g., Fig. 2A bottom). As such, these units were classified as Ramping units. Units that did not exhibit significant firing rate changes during the ITIs were considered to have no response (33\%). Figure 2E depicts the change in fraction of responsive units by type, with average percent time freezing during the CS overlaid; Phasic units exhibit significant firing rate changes prior to the emergence of CS-evoked freezing, indicating that the units may encode uncertainty or initial learning. On the other hand, Ramping units primarily exhibit significant rate changes following an increase in CS-evoked freezing, suggesting that they may encode certainty or late learning.

\section{Neural responses to the US $_{\text {post }}$ and ITI periods}

Although accurate recording during the footshock is not possible due to electrical interference from the grid floor occluding the signal during the 2 sec shock, we observed prolonged responses immediately following shock delivery, in some cases lasting upwards of $20 \mathrm{sec}$ in both Phasic (94.6\%) and Ramping (80\%) cells (Fig. 2D). Using each unit's maximum absolute $Z$ score of the three bins (i.e., $30 \mathrm{sec}$ window) following each shock (US $\mathrm{Sost}_{\text {t) }}$, a $3 \times 5$ mixed-design ANOVA revealed an interaction between cell type and trial $\left(F_{(8,300)}=7.793, P<0.00001\right)$, whereby on average, Phasic cells showed a population-wide gradual decrease in their

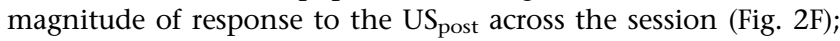
post hoc analysis revealed that response magnitude differed significantly on trials $3-5$ versus trial $1(P<0.05)$. Alternatively, Ramping cells exhibited a population-wide increase in the magnitude of response across the session, with peak magnitude following US 4; post hoc tests showed that trials 4 and 5 differed significantly compared to trial $1,(P<0.05)$. No Response cells did not show any significant population encoding of the US across the session.

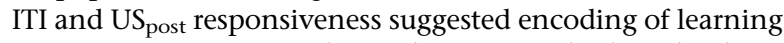
by some BNST units. As such, to determine whether shock response magnitude was an indication of fear learning, for units that were responsive to the US (47 of 79) we used simple linear regression to compare the magnitude of each unit's response to the $\mathrm{US}_{\text {post }}$ period (i.e., the maximum $\mathrm{z}$ score of the three bins following each shock) with freezing during the subsequent CS (Fig. 2G). We found that Phasic cell encoding during the postshock period following US 1 significantly predicted percent time spent freezing during CS $2\left(F_{(1,35)}=6.081, P=0.019, r=-0.390\right)$ such that the greater the firing rate during the postshock period, the less the freezing during the subsequent CS. US post $_{\text {responsiveness did not }}$ predict CS freezing in Ramping units $\left(F_{(1,19)}=0.530, P=0.476, r=\right.$ 0.169 ) or in Phasic units on any other trial. Results suggest that Phasic units may primarily encode attention or uncertainty of aversive contingency, and thus are negatively correlated with early fear learning.

\section{Neural responses during cued fear retrieval}

Neurons recorded during CS retrieval $(n=81)$ were analyzed to determine whether firing rate changes over the session reflected similarities with the Phasic and/or Ramping cells recorded during acquisition. To determine stimuli responsiveness across the retrieval session, firing rates were analyzed separately for early (i.e., 1-5) and late (i.e., 6-10) trials. Similar to acquisition, recording data for CS retrieval also took into consideration the ITI period in addition to CS presentations. A unit was considered to be CS-only responsive if both its $Z$-scored firing rate for any $10 \mathrm{sec}$ bin during any CS window had a $Z$ score of $>2.58$ or $<-2.58$, and its firing rate $Z$-score during bins of the ITI period (one $10 \mathrm{sec}$ bin per ITI) did not exceed \pm 2.58 . BNST was minimally responsive to CS-only presentations; only $3.7 \%$ ( 3 of 81 units) were responsive to early CS presentations (Fig. 2H top), and 4.9\% (4 of 81) during late CS presentations. No units were responsive to only the CS during both early and late trials. A slightly greater proportion of units was responsive during the ITI periods; $9.9 \%$ (8 of 81 ) of units in early trials and $16 \%$ (13 of 81 ) of units in late trials exhibited significantly altered firing rates during the ITI period. Similar to the 

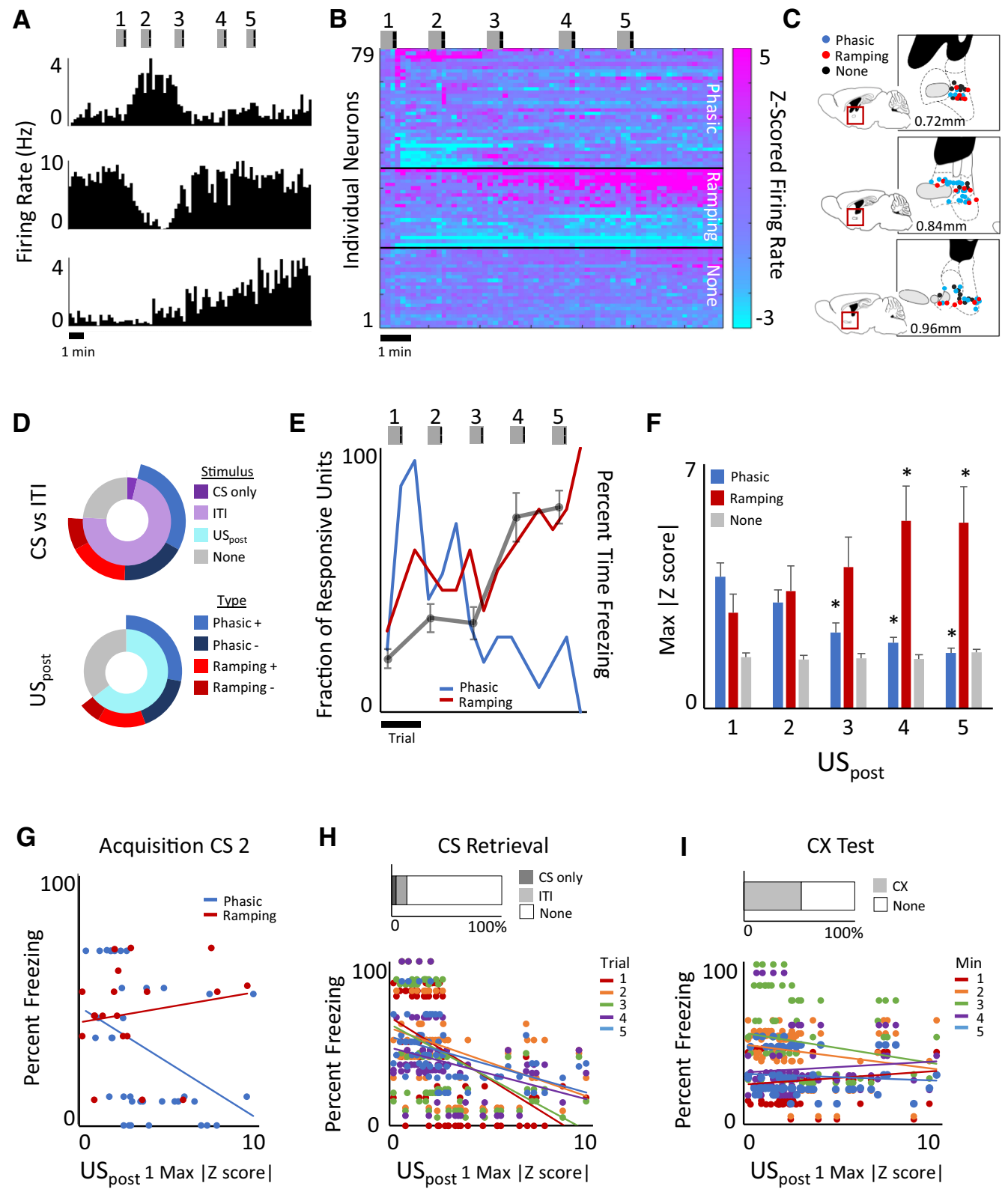

Figure 2. BNST phasic encoding predicts within- and across session fear expression. ( $A$ ) Perievent time histograms (PETHs; 10 sec bins) of representative BNST units recorded during the cued fear acquisition session. Phasic units $(n=34$ of 79) exhibited significant firing rate changes following early CS-US pairings that returned to baseline by later trials (top, middle), while Ramping units ( $n=19$ of 79) exhibited gradual, sustained firing rate changes that emerged some time after the first shock presentation and persisted throughout the session (bottom). (B) Population heat plot of $Z$ scored activity (relative to 3 min baseline) of all units recorded across the acquisition session (10 sec bins, organized from greatest to least $Z$ scored US $S_{\text {post }}$ response for each unit classification type). Phasic units exhibited significant changes in spike rate following US $S_{\text {post }} 1$ or 2 , while Ramping units exhibited significant rate changes lasting through the end of the session. (C) Histological reconstruction of recorded units, color coded by unit type. Blue = Phasic, red = Ramping, and black= no response. Placements overlaid on sagittal atlas sections, $0.72,0.84$, and $0.96 \mathrm{~mm}$ lateral relative to midline. $(D)$ The majority of units recorded during acquisition were responsive to the ITI (top, lilac) as well as the US post periods (bottom, aqua). Very few units were responsive only to the CS-on period (top, violet). ITI and US post responsive units were comprised of both Phasic (blue) and Ramping (red) units. Lighter blue and red versus darker blue and red shading indicate the proportion of units that exhibited significantly increased versus decreased firing rates relative to baseline, respectively. $(E)$ Average freezing behavior (gray) overlaid on line graphs depicting the fraction of responsive Phasic (blue) and Ramping (red) units for the CS-on, US post, and ITI periods across trials. As freezing expression increased across trials, fraction of responsive Phasic units decreased as the fraction of responsive

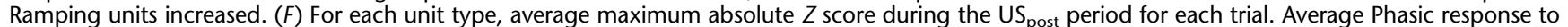
the US $S_{\text {post }}$ decreased across trials, while average Ramping response to the US $S_{\text {post }}$ increased across trials. $(G)$ Responsiveness to the first $U S_{\text {post }}$ period negatively predicted freezing behavior during the subsequent CS presentation for Phasic, but not Ramping, units. $(H)$ On day 2, very few of the 81 units recorded were responsive to either the CS-only or ITI periods (top). However, acquisition day responsiveness to the first US post period negatively predicted CS-evoked freezing behavior during early trials in Context B $24 \mathrm{~h}$ later. (I) About half of all units recorded on day $3(n=74)$ when mice returned to Context A were responsive to the context. Unlike previous days, responsiveness to the first US $S_{\text {post }}$ period on acquisition day did not predict freezing to the context on day 3. Panels $A, B$, and $E$ : Gray boxes represent CS-on times, and black vertical bars indicate time of US delivery. Data in $E$ and $F$ represent the mean $\pm S$.E.M. $\left({ }^{*}\right) P<0.05$. 
CS-only responsive cells, units responsive during the ITI rarely responded during both early and late trials (three of 81), suggesting that BNST neurons primarily encoded phasic changes during the CS retrieval session as opposed to sustained activity seen in Ramping units the day prior.

Next, we investigated whether performance on fear retrieval could be predicted based on population-wide BNST encoding during fear acquisition, since neural magnitude of response to the first shock on acquisition day predicted within session freezing. Indeed, the magnitude of individual units' responsiveness to the initial shock during acquisition correlated significantly with freezing expression during each of the five early CS retrieval trials $(r=-0.514$, $-0.386,-0.451,-0.323,-0.462, P<0.001)$, such that the greater the magnitude of response to the postshock period, the less CS-evoked freezing the animal displayed (Fig. 2H bottom). Similar to acquisition, this suggests that greater BNST encoding following the first tone-shock pairing predicted less overall fear learning (as indexed by freezing expression) in addition to within session learning, which could reflect aversive outcome uncertainty.

\section{Neural responses during context fear retrieval}

Mice were returned to the acquisition context on day 3 to assess contextual fear learning; as there was no baseline period to analyze, spikes recorded during exposure to the context were binned into 1-min blocks and normalized to each unit's homecage firing rate (i.e., $3 \mathrm{~min}$ recording occurring just prior to the animal being placed into the acquisition context). Similar to above, units were considered to be responsive to the context if their $Z$ score for that block exceeded \pm 2.58 . We found $52 \%$ of units recorded ( 28 of 74) to significantly change their firing rate after returning to the acquisition context (Fig. 2I top) during at least one of the 1-min blocks. Unlike acquisition and CS retrieval, however, unit responsiveness to the first shock pairing on acquisition day did not predict freezing to the context on day 3 during any time block $(r=0.13,-0.221,-0.179,0.09,0.08, P>0.05$; Fig. 2I bottom).

\section{Discussion}

Electrophysiological recordings of BNST neurons during fear acquisition revealed two subpopulations responsive to the task: Ramping cells gradually exhibited firing rate changes that persisted throughout the rest of the session; the fraction of Ramping units

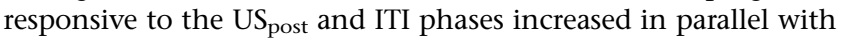
magnitude of freezing expression as mice learned the CS-US contingency. Conversely, Phasic units exhibited significant firing rate changes following the initial tone-shock pairings that returned to baseline before the last trials. This Phasic cell encoding predicted both within- and across-session learning because Phasic units' magnitude of responsiveness following the first shock presentation negatively correlated with freezing expression during the subsequent CS, as well as freezing during early CS presentations $24 \mathrm{~h}$ later during cued fear retrieval. These findings suggest that Phasic BNST activity during non-CS periods of cued fear learning may contribute to the acquisition and retention of cued fear.

BNST Phasic neurons maximally encoded the US $S_{\text {post }}$ period following the unexpected delivery of shock in early acquisition trials. These data echo previous electrophysiological findings that components of neural fear circuitry (i.e., lateral amygdala (LA) and periaqueductal gray (PAG) neurons) preferentially encode unsignaled versus signaled shock, and consequently, neural encoding decreases across fear acquisition sessions (Johansen et al. 2010). Connections between PAG and amygdala modulate fear learning and expression based on instructive signaling and feedback (Johansen et al. 2010; Ozawa et al. 2017). It has been proposed that PAG may indirectly convey nociceptive information related to shock to the LA to enable plasticity and induce fear learning (Kim et al. 2013a; Herry and Johansen 2014). But since PAG does not directly project to LA, regions such as thalamic nuclei or anterior cingulate cortex have been proposed as mediators (Shi and Davis 1999; Lanuza et al. 2004; Tang et al. 2005; McNally et al. 2011; Herry and Johansen 2014). However, based upon Phasic US ${ }_{\text {post }}$ signaling recorded here, we propose BNST as an additional potential instructor of fear learning. BNST has been shown to encode affective aspects of pain (Deyama et al. 2007; Morano et al. 2008; Minami and Ide 2015), and it is well-situated to relay information to the amygdala; PAG mediates nociception via projections to BNST (Li et al. 2016), and in turn, BNST projects to subregions of the amygdala including LA, basal (BA), and central (CeA) nuclei (Dong et al. 2000; Gungor et al. 2015; Krüger et al. 2015). As such, BNST signaling may relay information related to noxious events to inform future defensive response selection. This is evidenced not only by the ability of the magnitude of responsiveness following the first shock to predict CS-evoked freezing behavior on the subsequent trial, but also its ability to predict cued freezing expression $24 \mathrm{~h}$ later during CS retrieval.

While our findings suggest a key mediating contribution of the BNST for fear learning, this role does not appear to be necessary for such learning under normal circumstances. Several past studies have shown that BNST is not necessary for some types of fear learning (Gewirtz et al. 1998; Hammack et al. 2004; Sullivan et al. 2004; Waddell et al. 2006; Duvarci et al. 2009). However, the importance of the BNST can be unmasked following damage to the basolateral (BLA) amygdala (Poulos et al. 2010). Poulos et al. (2010) showed that extended fear conditioning (i.e., $>5$ trials) can result in withinand across-session freezing following damage to the BLA, so long as the BNST was intact. Importantly though, lesions to either BLA or BNST attenuated within-session learning during the initial trials (i.e., 1-4), and BNST lesions alone also impaired fear recall $24 \mathrm{~h}$ later. These results suggest that BNST does in fact play a role in fear learning, both during initial US occurrences as well as long-term retention. Phasic signaling in BNST reported here, which predicted both within- and across-session learning supports this idea. Furthermore, the parallel increase in freezing and Ramping cell responsiveness across acquisition also indicates the potential involvement of Ramping signaling in within-session learning.

One caveat, however, is that compensatory BNST fear learning has been demonstrated in contextual (Poulos et al. 2010) but not cued fear conditioning (Zimmerman and Maren 2011). Although evidence here supports a role for BNST involvement in cued fear learning, we like others did not find sufficient evidence to conclude that BNST encodes fear cues specifically. Rather, responsive neurons exhibited firing rate changes during the US $\mathrm{S}_{\text {post }}$ and ITI periods when stimuli present included only the context. Several lines of evidence have shown that BNST encodes contextual fear conditioning (Sullivan et al. 2004; Waddell et al. 2006; Zimmerman and Maren 2011; Davis and Walker 2014; Hammack et al. 2015). During early cued fear learning, some contextual conditioning takes place because the associative strength of the US has not been fully attributed to the CS (Rescorla and Wagner 1972). Thus, for Phasic BNST neurons specifically, it is possible that responsiveness during non-CS periods is indicative of some degree of contextual fear learning, which subsides after repeated CS-US pairings as the majority of associative strength shifts to the CS.

Past in vivo electrophysiology studies have shown that LA and PAG firing rate changes in response to fear cues often correlate with fear expression in real-time (Blair et al. 2003; Johansen et al. 2010; Halladay and Blair 2015). Here, subpopulations differ in this regard since Phasic signaling inversely predicted subsequent cue-evoked fear expression, but Ramping cell responsiveness and freezing increased in parallel across the session. Some recent recording studies 
have identified opposing BNST populations that distinctly encode either anxiogenic or anxiolytic behaviors (Jennings et al. 2013; Kim et al. 2013a). While our data do not suggest Phasic and Ramping cells oppose each other directly, the differences in neural response patterns highlight the heterogeneity of neural activity in BNST previously reported (Gungor and Paré 2016). One important distinction here versus past recording studies is that Phasic ITI signaling predicted behavior as far as 30-90 sec in the future (i.e., during CS presentation), rather than coinciding with concurrent behavioral expression. Similarly, while Ramping cell responsivity mirrored increase in freezing behavior over time, we did not find evidence that Ramping cells directly modulated behavior in real time. This seems to reflect sustained encoding of aversive information, in support of previous studies implicating BNST in modulating responses during sustained or long-duration aversive states (Waddell et al. 2006; Walker and Davis 2008; Davis et al. 2010).

It is worth noting that the increase in Ramping cell responsiveness observed across the acquisition session is reminiscent of past studies showing an increase in CeA neural responsiveness to the CS across fear learning as freezing increases (Ciocchi et al. 2010; Duvarci et al. 2011). As BNST-projecting CeA corticotropinreleasing factor (CRF) neurons are necessary for sustained fear expression (Asok et al. 2018), it seems plausible that BNST Ramping cells may receive input from CeA that drives the long-duration ITI responsiveness reported here. This would be an interesting direction for future circuit-specific studies.

Finally, while the majority of Phasic and Ramping units significantly increased their firing rate in response to the ITI, a fairly substantial number of both unit types were classified as such based on a significantly inhibited response relative to baseline. Despite these contrasting response patterns, we did not find any meaningful functional distinction between units that increased versus decreased firing rate during the ITI relative to baseline, again indicative of the heterogeneity of cell-types found in the BNST (Gungor and Paré 2016). There is some evidence that the various functional roles for the BNST may be distributed anatomically within subregions of the BNST (Lebow and Chen 2016). Units recorded here were primarily located in medial and lateral regions of the posterior BNST, with few in dorsal or anterior BNST subregions. But this does not rule out contributions of more anteriorly or dorsally located BNST cells to mechanisms involved in cued fear learning. It stands to reason that the role of the BNST in cued fear learning may involve a coordinated effort from a diverse network of cells that may be widely distributed in the BNST.

In summary, we identified two functionally discrete subpopulations of BNST neurons that encode the US post $_{\text {and ITI periods }}$ of cued fear learning. Phasic signaling in BNST may instruct both within- and across-session fear expression by relaying information specific not to the CS, but rather, to the longer duration periods between acquisition trials. Future studies such as those including multisite in vivo recordings will be necessary to more fully understand the implications of phasic neural signaling in BNST during cued fear learning.

\section{Materials and Methods}

\section{Subjects}

Male C57BL/6J mice were obtained from The Jackson Laboratory (Bar Harbor, ME; https://www.jax.org/strain/000664) at 7-8 wk of age and housed in pairs in a temperature $\left(72 \pm 5^{\circ} \mathrm{F}\right)$ and humidity $(45 \pm 15 \%)$ controlled vivarium, under a $12 \mathrm{~h}$ light-dark cycle (lights on at 06:30 h). All procedures were approved by the NIAAA Animal Care and Use Committee and followed the NIH guidelines outlined in Using Animals in Intramural Research, as well as the local Animal Care and Use Committees.

\section{Behavioral procedures}

Behavioral sessions were conducted using MedPC (Med Associates, Fairfax, VT) in conjunction with Plexon recording equipment described below. Acquisition took place on day 1 in Context A, $27 \times$ $27 \times 11 \mathrm{~cm}$ chamber with a metal rod floor for shock delivery, cleaned with a $69 \%$ water $/ 30 \%$ ethanol $/ 1 \%$ vanilla-extract solution. Acquisition consisted of a 180 -sec baseline period followed by five pairings of a pure tone $\mathrm{CS}(30 \mathrm{sec}, 3 \mathrm{kHz}, 75 \mathrm{~dB})$ coterminating with a footshock US ( $2 \mathrm{sec}, 0.6 \mathrm{~mA}$ ), with variable ITIs between 60-120 sec. Mice were tested for cue-evoked freezing during CS retrieval $24 \mathrm{~h}$ later, which took place in Context B, $20 \mathrm{~cm}$ diameter Plexiglas cylinder with a solid, opaque floor and cleaned with a $99 \%$ water/1\% acetic acid solution. The session consisted of a 180 -sec baseline period followed by 10 CS presentations (10 sec ITI). Twenty-four hours following retrieval, mice were returned to Context A for a 5-min context (CX) test. Freezing behavior was scored using the automated freezing function in CinePlex Editor (Plexon Inc.) and verified using hand scoring by blind experimenters. We used the automated scores for analyses due to the high temporal resolution required for spike timing data; freezing intervals used to assess fear expression in the behavioral analysis were taken from baseline and CS-on periods during acquisition and retrieval, as well as 1-min blocks during the context test.

\section{In vivo neuronal recordings}

At least $1 \mathrm{wk}$ prior to experimentation, mice $(n=10)$ were surgically implanted with fixed microelectrode arrays (Innovative Neurophysiology, Durham, NC) containing two rows of eight tungsten electrodes $(35 \mu \mathrm{m}$ diameter), with $150 \mu \mathrm{m}$ electrodespacing and $200 \mu \mathrm{m}$ row spacing, unilaterally implanted in BNST (array center at $0.3 \mathrm{~mm}$ anterior, $0.8 \mathrm{~mm}$ lateral, and $4.15 \mathrm{~mm}$ ventral relative to Bregma). Electrophysiological recordings were conducted during acquisition, CS retrieval, and CX test sessions, using the OmniPlex D Neural Data Acquisition System, with simultaneous behavioral analysis via CinePlex Behavioral Research Systems (Plexon Inc.). Waveforms exceeding a preset voltage threshold were digitized at $40 \mathrm{kHz}$. Manual cluster analysis and inspection of waveforms and inter-spike intervals were performed offline using Plexon Offline Sorter. Spike and timestamp information were integrated and analyzed using NeuroExplorer (NexTechnologies).

Following completion of experiments, mice were anesthetized with $2 \%$ Isoflurane (in oxygen, $2 \mathrm{~L} / \mathrm{min}$ ), and a current stimulator (S48 Square Pulse Stimulator, Grass Technologies) was used to deliver 2 sec of $40 \mu \mathrm{A}$ DC current through each electrode to make a small marking lesion. $24 \mathrm{~h}$ later, mice were overdosed with ketamine/xylazine and perfused transcardially with $4 \%$ paraformaldehyde in phosphate buffered saline. Brains were sectioned on a vibratome (Leica VT100S) and $50 \mu \mathrm{m}$ sections slide-mounted and stained for acetylcholinesterase (Gunduz-Cinar et al. 2019) for histological verification of electrode placements. Only units from electrodes confirmed to be located within BNST were included in the analyses.

\section{Experimental design and statistical analyses}

All animal and unit $\mathrm{n}$ values are described for each of the three behavioral sessions in the results below. Behavior data were analyzed using one- or two-way analysis of variance (ANOVA) and Tukey's honest significant difference (HSD) test for planned post hoc comparisons. For comparison of behavior during early versus late trials on day 2 , data were analyzed using paired sample Student's $t$-test. Results are presented as the mean \pm S.E.M.

Spike data were normalized and analyzed as previously described (Halladay and Blair 2015; Gamble-George et al. 2016; Marcinkiewcz et al. 2016; Gunduz-Cinar et al. 2019; Hardaway et al. 2019; Halladay et al. 2019). Classification of cell types based on responsiveness to events described below in Results. Comparisons between unit firing rates and behavior were made using simple linear regression or bivariate correlation. 


\section{Competing interest statement}

The authors have no financial interests or conflicts of interest to disclose.

\section{Acknowledgments}

This research was funded by the NIAAA Intramural Research Program and Santa Clara University.

\section{References}

Asok A, Draper A, Hoffman AF, Schulkin J, Lupica CR, Rosen JB. 2018. Optogenetic silencing of a corticotropin-releasing factor pathway from the central amygdala to the bed nucleus of the stria terminalis disrupts sustained fear. Mol Psychiatry 23: 914-922. doi:10.1038/mp.2017.79

Blair HT, Tinkelman A, Moita MA, LeDoux JE. 2003. Associative plasticity in neurons of the lateral amygdala during auditory fear conditioning. Ann N Y Acad Sci 985: 485-487. doi:10.1111/j.1749-6632.2003.tb07106.x

Ciocchi S, Herry C, Grenier F, Wolff SB, Letzkus JJ, Vlachos I, Ehrlich I, Sprengel R, Deisseroth K, Stadler MB, et al. 2010. Encoding of conditioned fear in central amygdala inhibitory circuits. Nature 468: 277-282. doi:10.1038/nature09559

Daldrup T, Lesting J, Meuth P, Seidenbecher T, Pape HC. 2016. Neuronal correlates of sustained fear in the anterolateral part of the bed nucleus of the stria terminalis. Neurobiol Learn Mem 131: 137-146. doi:10.1016/j .nlm.2016.03.020

Davis M. 1998. Anatomic and physiologic substrates of emotion in an animal model. J Clin Neurophysiol 15: 378-387. doi:10.1097/00004691199809000-00002

Davis M, Walker DL. 2014. Role of bed nucleus of the stria terminalis and amygdala AMPA receptors in the development and expression of context conditioning and sensitization of startle by prior shock. Brain Struct Funct 219: 1969-1982. doi:10.1007/s00429-013-0616-5

Davis M, Walker DL, Miles L, Grillon C. 2010. Phasic vs sustained fear in rats and humans: role of the extended amygdala in fear vs anxiety. Neuropsychopharmacol 35: 105-135. doi:10.1038/npp.2009.109

Deyama S, Nakagawa T, Kaneko S, Uehara T, Minami M. 2007. Involvement of the bed nucleus of the stria terminalis in the negative affective component of visceral and somatic pain in rats. Behav Brain Res 176: 367-371. doi:10.1016/j.bbr.2006.10.021

Dong H, Petrovich GD, Swanson LW. 2000. Organization of projections from the juxtacapsular nucleus of the BST: a PHAL study in the rat. Brain Res 859: 1-14. doi:10.1016/S0006-8993(99)02246-5

Duvarci S, Bauer EP, Paré D. 2009. The bed nucleus of the stria terminalis mediates inter-individual variations in anxiety and fear. J Neurosci 29: 10357-10361. doi:10.1523/JNEUROSCI.2119-09.2009

Duvarci S, Popa D, Paré D. 2011. Central amygdala activity during fear conditioning. J Neurosci 31: 289-294. doi:10.1523/JNEUROSCI.4985-10 .2011

Fendt M, Fanselow MS. 1999. The neuroanatomical and neurochemical basis of conditioned fear. Neurosci Biobehav Rev 23: 743-760. doi:10 .1016/S0149-7634(99)00016-0

Gamble-George JC, Baldi R, Halladay L, Kocharian A, Hartley N, Silva CG, Roberts H, Haymer A, Marnett LJ, Holmes A, et al. 2016.

Cyclooxygenase-2 inhibition reduces stress-induced affective pathology. Elife 5: e14137. doi:10.7554/eLife.14137

Gewirtz JC, McNish KA, Davis M. 1998. Lesions of the bed nucleus of the stria terminalis block sensitization of the acoustic startle reflex produced by repeated stress, but not fear-potentiated startle. Prog Neuropsychopharmacol Biol Psychiatry 22: 625-648. doi:10.1016/ S0278-5846(98)00028-1

Goode TD, Maren S. 2017. Role of the bed nucleus of the stria terminalis in aversive learning and memory. Learn Mem 24: 480-491. doi:10.1101/lm .044206 .116

Goode TD, Kim JJ, Maren S. 2015. Reversible inactivation of the bed nucleus of the stria terminalis prevents reinstatement but not renewal of extinguished fear. eNeuro 2: e0037-15. doi:10.1523/ENEURO.0037-15 .2015 .

Goode TD, Ressler RL, Acca GM, Miles OW, Maren S. 2019. Bed nucleus of the stria terminalis regulates fear to unpredictable threat signals. Elife 8: e46525. doi:10.7554/eLife.46525

Gunduz-Cinar O, Brockway E, Lederle L, Wilcox T, Halladay LR, Ding Y, Oh H, Busch EF, Kaugars K, Flynn S, et al. 2019. Identification of a novel gene regulating amygdala-mediated fear extinction. Mol Psychiatry 24: 601-612. doi:10.1038/s41380-017-0003-3

Gungor NZ, Paré D. 2016. Functional heterogeneity in the bed nucleus of the stria terminalis. J Neurosci 36: 8038-8049. doi:10.1523/JNEUROSCI $.0856-16.2016$
Gungor NZ, Yamamoto R, Paré D. 2015. Optogenetic study of the projections from the bed nucleus of the stria terminalis to the central amygdala. J Neurophysiol 114: 2903-2911. doi:10.1152/jn.00677.2015

Halladay LR, Blair HT. 2015. Distinct ensembles of medial prefrontal cortex neurons are activated by threatening stimuli that elicit excitation vs. inhibition of body movement. J Neurophysiol 114: 793-807. doi:10 $.1152 / j n .00656 .2014$

Halladay LR, Kocharian A, Piantadosi PT, Authement ME, Lieberman AG, Spitz NA, Coden K, Glover L, Costa VD, Alvarez VA, et al. 2019. Prefrontal regulation of punished ethanol self-administration. Biol Psychiatry doi:10.1016/j.biopsych.2019.10.030

Hammack SE, Richey KJ, Watkins LR, Maier SF. 2004. Chemical lesion of the bed nucleus of the stria terminalis blocks the behavioral consequences of uncontrollable stress. Behav Neurosci 118: 443-448. doi:10.1037/ 0735-7044.118.2.443

Hammack SE, Todd TP, Kocho-Schellenberg M, Bouton ME. 2015. Role of the bed nucleus of the stria terminalis in the acquisition of contextual fear at long or short context-shock intervals. Behav Neurosci 129: 673678. doi:10.1037/bne0000088

Hardaway JA, Halladay LR, Mazzone CM, Pati D, Bloodgood DW, Kim M, Jensen J, DiBerto JF, Boyt KM, Shiddapur A, et al. 2019. Central amygdala prepronociceptin-expressing neurons mediate palatable food consumption and reward. Neuron 102: 1037-1052. doi:10.1016/j .neuron.2019.03.037

Haufler D, Nagy FZ, Pare D. 2013. Neuronal correlates of fear conditioning in the bed nucleus of the stria terminalis. Learn Mem 20: 633-641. doi:10 $.1101 / \mathrm{lm} .031799 .113$

Herry C, Johansen JP. 2014. Encoding of fear learning and memory in distributed neuronal circuits. Nat Neurosci 17: 1644-1654. doi:10.1038/ nn.3869

Jennings JH, Sparta DR, Stamatakis AM, Ung RL, Pleil KE, Kash TL, Stuber GD. 2013. Distinct extended amygdala circuits for divergent motivational states. Nature 496: 224-228. doi:10.1038/nature12041

Johansen JP, Tarpley JW, LeDoux JE, Blair HT. 2010. Neural substrates for expectation-modulated fear learning in the amygdala and periaqueductal gray. Nat Neurosci 13: 979-986. doi:10.1038/nn.2594

Kim EJ, Horovitz O, Pellman BA, Tan LM, Li Q, Richter-Levin G, Kim JJ. 2013a. Dorsal periaqueductal gray-amygdala pathway conveys both innate and learned fear responses in rats. Proc Natl Acad Sci 110: 1479514800. doi:10.1073/pnas.1310845110

Kim SY, Adhikari A, Lee SY, Marshel JH, Kim CK, Mallory CS, Lo M, Pak S, Mattis J, Lim BK, et al. 2013b. Diverging neural pathways assemble a behavioural state from separable features in anxiety. Nature 496: 219-223. doi:10.1038/nature12018

Krüger O, Shiozawa T, Kreifelts B, Scheffler K, Ethofer T. 2015. Three distinct fiber pathways of the bed nucleus of the stria terminalis to the amygdala and prefrontal cortex. Cortex 66: 60-68. doi:10.1016/j.cortex.2015.02 .007

Lanuza E, Nader K, LeDoux JE. 2004. Unconditioned stimulus pathways to the amygdala: effects of posterior thalamic and cortical lesions on fear conditioning. Neuroscience 125: 305-315. doi:10.1016/j.neuroscience .2003.12.034

Lebow MA, Chen A. 2016. Overshadowed by the amygdala: the bed nucleus of the stria terminalis emerges as key to psychiatric disorders. $\mathrm{Mol}$ Psychiatry 21: 450-463. doi:10.1038/mp.2016.1

LeDoux JE. 2000. Emotion circuits in the brain. Annu Rev Neurosci 23: 155-184. doi:10.1146/annurev.neuro.23.1.155

LeDoux JE, Iwata J, Cicchetti P, Reis DJ. 1988. Different projections of the central amygdaloid nucleus mediate autonomic and behavioral correlates of conditioned fear. J Neurosci 8: 2517-2529. doi:10.1523/ JNEUROSCI.08-07-02517.1988

Li C, Sugam JA, Lowery-Gionta EG, McElligott ZA, McCall NM, Lopez AJ, McKlveen JM, Pleil KE, Kash TL. 2016. Mu opioid receptor modulation of dopamine neurons in the periaqueductal gray/dorsal raphe: a role in regulation of pain. Neuropsychopharmacol 41: 2122-2132. doi:10.1038/ npp.2016.12

Marcinkiewcz CA, Mazzone CM, D'Agostino G, Halladay LR, Hardaway JA, DiBerto JF, Navarro M, Burnham N, Cristiano C, Dorrier CE, et al. 2016. Serotonin engages an anxiety and fear-promoting circuit in the extended amygdala. Nature 537: 97-101. doi:10.1038/nature19318

Maren S. 2001. Neurobiology of Pavlovian fear conditioning. Annu Rev Neurosci 24: 897-931. doi:10.1146/annurev.neuro.24.1.897

McNally GP, Johansen JP, Blair HT. 2011. Placing prediction into the fear circuit. Trends Neurosci 34: 283-292. doi:10.1016/j.tins.2011.03.005

Minami M, Ide S. 2015. How does pain induce negative emotion? Role of the bed nucleus of the stria terminalis in pain-induced place aversion. Curr Mol Med 15: 184-190. doi:10.2174/ 1566524015666150303002336

Morano TJ, Bailey NJ, Cahill CM, Dumont EC. 2008. Nuclei-and condition-specific responses to pain in the bed nucleus of the stria terminalis. Prog Neuropsychopharmacol Biol Psychiatry 32: 643-650. doi:10.1016/j.pnpbp.2007.11.003 
Naaz F, Knight LK, Depue BE. 2019. Explicit and ambiguous threat processing: functionally dissociable roles of the amygdala and the bed nucleus of the stria terminalis. JCogn Neurosci 31: 543-559. doi:10.1162/ jocn_a_01369

Orsini CA, Maren S. 2012. Neural and cellular mechanisms of fear and extinction memory formation. Neurosci Biobehav Rev 36: 1773-1802. doi:10.1016/j.neubiorev.2011.12.014

Ozawa T, Ycu EA, Kumar A, Yeh LF, Ahmed T, Koivumaa J, Johansen JP. 2017. A feedback neural circuit for calibrating aversive memory strength. Nat Neurosci 20: 90-97. doi:10.1038/nn.4439

Poulos AM, Ponnusamy R, Dong HW, Fanselow MS. 2010. Compensation in the neural circuitry of fear conditioning awakens learning circuits in the bed nuclei of the stria terminalis. Proc Natl Acad Sci 107: 14881-14886. doi:10.1073/pnas.1005754107

Rescorla RA, Wagner AR. 1972. A theory of Pavlovian conditioning: variations in the effectiveness of reinforcement and nonreinforcement. In Classical conditioning II: current research and theory (ed. Black $\mathrm{AH}$, Prokasy WF), pp. 64-99. Appleton-Century-Crofts, New York.

Shi C, Davis M. 1999. Pain pathways involved in fear conditioning measured with fear-potentiated startle: lesion studies. J Neurosci 19: 420-430. doi:10.1523/JNEUROSCI.19-01-00420.1999

Sullivan GM, Apergis J, Bush DE, Johnson LR, Hou M, Ledoux JE. 2004. Lesions in the bed nucleus of the stria terminalis disrupt corticosterone and freezing responses elicited by a contextual but not by a specific cue-conditioned fear stimulus. Neuroscience 128: 7-14. doi:10.1016/j .neuroscience.2004.06.015

Tang J, Ko S, Ding HK, Qiu CS, Calejesan AA, Zhuo M. 2005. Pavlovian fear memory induced by activation in the anterior cingulate cortex. Mol Pain 1: 6. doi:10.1186/1744-8069-1-6

Waddell J, Morris RW, Bouton ME. 2006. Effects of bed nucleus of the stria terminalis lesions on conditioned anxiety: aversive conditioning with long-duration conditional stimuli and reinstatement of extinguished fear. Behav Neurosci 120: 324-336. doi:10.1037/0735-7044.120.2.324

Walker DL, Davis M. 2008. Role of the extended amygdala in short-duration versus sustained fear: a tribute to Dr. Lennart Heimer. Brain Struct Funct 213: 29-42. doi:10.1007/s00429-008-0183-3

Zelikowsky M, Bissiere S, Hast TA, Bennett RZ, Abdipranoto A, Vissel B, Fanselow MS. 2013. Prefrontal microcircuit underlies contextual learning after hippocampal loss. Proc Natl Acad Sci 110: 9938-9943. doi:10.1073/pnas.1301691110

Zimmerman JM, Maren S. 2011. The bed nucleus of the stria terminalis is required for the expression of contextual but not auditory freezing in rats with basolateral amygdala lesions. Neurobiol Learn Mem 95: 199_ 205. doi:10.1016/j.nlm.2010.11.002

Received September 8, 2019; accepted in revised form November 22, 2019. 


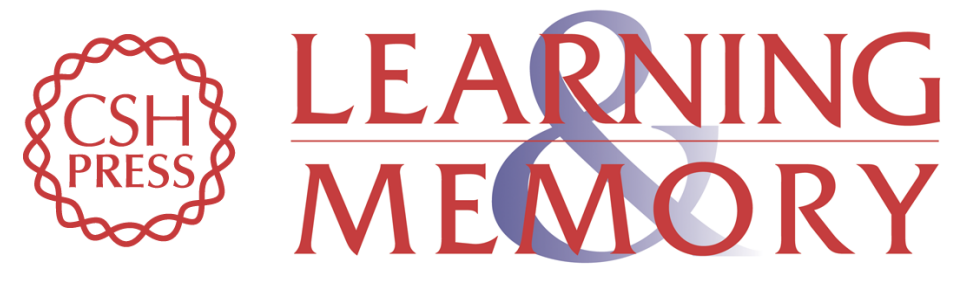

\section{Phasic signaling in the bed nucleus of the stria terminalis during fear learning predicts within- and across-session cued fear expression}

Max Bjorni, Natalie G. Rovero, Elissa R. Yang, et al.

Learn. Mem. 2020, 27:

Access the most recent version at doi:10.1101/lm.050807.119

References This article cites 53 articles, 11 of which can be accessed free at: http://learnmem.cshlp.org/content/27/3/83.full.html\#ref-list-1

Creative This article is distributed exclusively by Cold Spring Harbor Laboratory Press for the Commons first 12 months after the full-issue publication date (see

License http://learnmem.cshlp.org/site/misc/terms.xhtml). After 12 months, it is available under a Creative Commons License (Attribution-NonCommercial 4.0 International), as described at http://creativecommons.org/licenses/by-nc/4.0/.

Email Alerting Receive free email alerts when new articles cite this article - sign up in the box at the Service top right corner of the article or click here. 